\title{
Effect of Diode Laser 810nm in Hardness of Dental Ceramic
}

\author{
Mubarak M. Ahmed1,2, Abdelaziz Hagar Abdelrahman1,2*, Elhadi Mohieldin3, \\ Samia Omer Yagoub1 \\ ${ }^{1}$ Laser system Department, Laser Institute, Sudan University of Science and Technology, Khartoum, Sudan \\ ${ }^{2}$ Department of Physics, Faculty of Science and Arts at Al-Muznib, Qassim University, Al-Muznib, KSA \\ ${ }^{3}$ Restorative Dentistry, Faculty of Dentistry, University of Medical Science and Technology, Khartoum, Sudan \\ Email: ahay20004@yahoo.com
}

Received 20 March 2014; revised 21 April 2014; accepted 18 May 2014

Copyright (C) 2014 by authors and Scientific Research Publishing Inc.

This work is licensed under the Creative Commons Attribution International License (CC BY).

http://creativecommons.org/licenses/by/4.0/

(c) (7) Open Access

\section{Abstract}

This research studied the effect of diode laser $(810 \mathrm{~nm})$, with various power $(30,200,500) \mathrm{mW}$ in hardness of the material used in the combinations of teeth (ceramics). Hardness was measured for dental ceramic samples divided into four groups, each group containing ten test samples, before and after it irradiated with the diode laser with wavelength $810 \mathrm{~nm}$ and different power $(30,200$, 500) $\mathrm{mW}$, with irradiation power of $200 \mathrm{~mW}$ for duration two minutes and ten minutes to the third and fourth groups, and irradiation power of 30 and $500 \mathrm{~mW}$ for duration one minute for the last two groups. The results showed that the increase in the irradiated time of the samples from two minutes to ten minutes, as well as increased power from 30 to $500 \mathrm{~mW}$ does not have a significant effect in increasing the hardness of the ceramic material. This study found that the hardness ratio of the samples was increased up to $(18.28 \%)$, by irradiation of invisible diode laser $810 \mathrm{~nm}$, $30 \mathrm{~mW}$.

\section{Keywords}

Dental Ceramic, Invisible Laser, Irradiation, Hardness

\section{Introduction}

The laser now plays an important role in our everyday life. It has a wide variety of applications in industry, engineering and medicine [1] [2]. Therefore, it is not surprising to find many papers dealing with irradiation power in lasers applications [3]. Dental ceramics or porcelain is popular due to the demand for aesthetics and durability ${ }^{\bar{*}}$ Corresponding author. 
of restoration. Dental ceramics consist of mainly glass, porcelain or crystalline of structure, the physical or mechanical properties of ceramic are much closer to enamel than those of acrylic resins and method, ceramic also have a coefficient of thermal expansion very close to that of teeth [4].

Dental ceramics contain a crystal phase and a glass phase based on the silica structure, containing central $\mathrm{Si}^{4+}$ ion with four $\mathrm{O}^{-}$ions. It is not closely packed, having both covalent and ionic characteristics. The usual dental ceramic, is glassy in nature, with short-range crystallinity. The only true crystalline ceramic used at present in restorative dentistry is Alumina $\left(\mathrm{Al}_{2} \mathrm{O}_{3}\right)$, which is one of the hardest and strongest oxides known. The glass reacts with calcium and other ions forming salts and the cement sets [5].

Ceramic materials are used for variety of dental restoration; these include the fabrication of denture teeth, indirect restorative materials such as single crowns, fixed partial dentures; more recently the use of ceramic has been expanded to include inlays and onlays in posterior teeth, implants [6].

Classification of ceramics in dentistry is apparently an impossible task due to vast improvements made in the compositions; Dental ceramics may be classified according to several parameters, such as their use, microstructure (i.e., amount and type of crystalline phase and glass composition), manufacturing temperature, ceramic system, composition, and processing technique.

Lasers interactions with tissue are complicated and no single parameter alone will determine how the laser affects the tissue. Dental hard tissue applications include ablation of carious lesions, cavity preparation for restoration, caries detection, endodontic surgery, and the potential for caries preventive therapy. The parameters of prime concern in understanding desirable or undesirable tissue effects are wavelength, pulse duration, absorption properties, scattering, energy, flounce (energy/surface area), power density, repetition rate, number of pulses, pulse duration and pulse shape. A range of laser parameters have been found with which dental enamel can be treated to make it resistant to subsequent dissolution by acid during dental caries. Our studies have demonstrated that treatment of enamel by specific pulsed diode laser irradiation can markedly inhibit subsequent caries progression. During irradiation, heat causes carbonate loss from the carbonated hydroxyapatite mineral, converting it into a low solubility hydroxyapatite-like calcium phosphate.

\section{Materials and Methods}

In this work, diode of $810 \mathrm{~nm}$, tunable output power $(30,200,500) \mathrm{mW}$, Ora-laser jet Company Germany, was used [7].

Dental ceramic firing furnace, Centurion Q50 vacuum porcelain furnace , $(100-120) \mathrm{V}, 50 / 60 \mathrm{~Hz},(33 \times 33 \times$ 41) $\mathrm{cm}$ dimensions, computerized auto control and calibration, Maximum Pressing Firing Temperature $1204^{\circ}$.

The hardness tester $(\mathrm{TH} 160)$, with dimensions of $(268 \times 86 \times 50) \mathrm{mm}, 50 \mathrm{hr}$ Continuous work, Digiwork Instruments Company, Canada, used to provide a wide range for non-distractive test of hardness [8].

The dental ceramic layer was subjected to the test of strength to measure the hardness for each specimen before the laser irradiation (pre test), by using Birnell hardness test. After the irradiation of the all specimens, has been subjected to the hardness test (post test).

Principle of the Birnell hardness test an indenter (hard metal ball with diameter $\mathrm{D}$ ) is forced into the surface of the metals or test piece, and the diameter of the indentation $\mathrm{d}$ left the surface after removal of the force $\mathrm{F}$ is measured.

The Brinell hardness number, or simply the Brinell number, is obtained by dividing the load used, in kilograms, by the actual surface area of the indentation, in square millimeters. The result is a pressure measurement, but the units are rarely stated.

Birnell hardness is proportional to the equation obtained by dividing the test force by curved surface, area of the indentation with radius corresponding to half of the diameter of the ball [9].

$$
\begin{gathered}
B H N=\text { Constant } \times \frac{\text { Test Force }}{\text { Surface area of indentation }} \\
B H N=1.102 \times \frac{2 F}{\pi D\left(D-\sqrt{D^{2}-d^{2}}\right)}
\end{gathered}
$$

where: 
$B H N \equiv$ Brinell hardness number , $\mathrm{F} \equiv$ applied force in $\mathrm{kg} . \mathrm{D} \equiv$ diameter of indenter in $\mathrm{mm}$. $\mathrm{d} \equiv$ diameter of indentation in mm.

- UVmini-1240 UV-VIS Spectrophotometer of spectral scanning range of (190 to 1100) nm was used in this study to measured absorption spectrum of dental ceramic materials.UVmini-1240 features a variety of standard data acquisition modes [9].

- Dental ceramic materials used in this study are powder opaque $\mathrm{B}_{1}$, and dentine $\mathrm{B}_{1}$ from Ceramco 3 and used anickel chromium metal. Dental ceramic materials used in this study are powder opaque $\mathrm{B}_{1}$, and dentine $\mathrm{B}_{1}$ from Ceramco3.and used anickel chromium metal.

\subsection{Preparation of Ceramic Specimens}

First, anickel chromium as base metal alloy used to fabricate 40 specimens for ceramic material, measuring 10 $\mathrm{mm}$ in diameter and $4 \mathrm{~mm}$ in thickness of the metal plus a layer of $1.7 \mathrm{~mm}$ thickness of the ceramic material. Then, ceramic powder (dentin and opaque powder) was mixed with distilled water to form slurry, and then the mixed slurry was loaded into nickel chromium mold as a layer. Before that, the specimens were placed on a firing tray (Centurion Q50 Vacuum Porcelain Furnace) they were dried and sintered in a vacuum furnace according to manufacturer's specification at temperature of $850^{\circ} \mathrm{C}$. Figure 1 shows photographs of the prepared specimens.

\subsection{Procedure and Methods}

\section{Setup Procedure}

This part has been by using the diode laser from Ora-Laser jet system, invisible laser irradiation, wavelength $810 \mathrm{~nm}$, class 4 laser products, by using power of 30mW 200mW and $500 \mathrm{~mW}$, energy $0.5 \mathrm{~J}$, frequency $50 \mathrm{~Hz}$, pulse pause relation(PPR) 1:1, in a continuous mode (CW).

The experimental procedure was done by using Ora-Laser jet system, but forty specimens were used were irradiated at different ways.

First way, twenty specimens of dental ceramic divided into two groups, ten in each according to irradiated time, they irradiated with the diode laser $810 \mathrm{~nm}$, at same power of $200 \mathrm{~mW}$, different irradiation time beginning of two minutes for the first group, and change the time to ten minutes for the second group.

Second way, twenty specimens of dental ceramic divided into two groups, ten in each according to irradiated power, they irradiated with diode laser $810 \mathrm{~nm}$, at constant duration of one minute, but at variable power of 30 $\mathrm{mW}$ to the first group, and change to $500 \mathrm{~mW}$ for the second group. The irradiation of specimens is shown in Figure 2.

After the irradiation of specimens by the two ways, the specimens were subjected to the hardness test by using birnell hardness test. Figure 3 shows the method for hardness measurements of specimens before and after irradiation.

The experimental procedure was done as follows:

a) The hardness test for each specimen's dental ceramic layer was measured before the laser irradiation (pre-test), by using the hardness tester (TH 160) Birnell hardness test.

b) before begging irradiation the Goggles wired (protective eyewear) for safety.

c) Forty specimens of conventional dental ceramic were separated to four groups, ten specimens of each one.

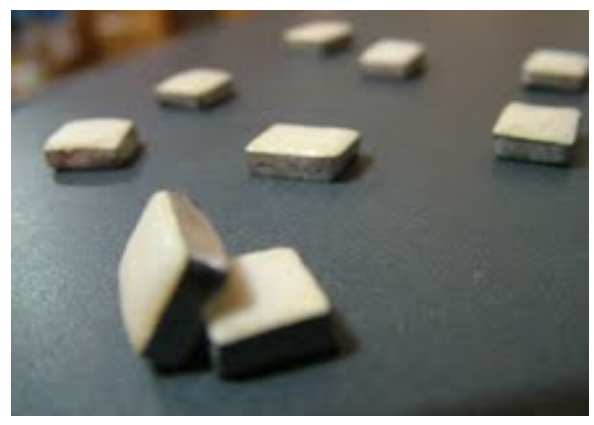

Figure 1. Photographs of the specimens. 
Each group was irradiated with diode laser $810 \mathrm{~nm} 0.5 \mathrm{~J}, 50 \mathrm{~Hz}$, pulse pause relation (PPR) 1:1, in a continuous mode (CW) at different in output power of $(30,200,500) \mathrm{mW}$ and time $(1,2,10)$ minutes as two way.

- Twenty specimens of dental ceramic divided into two groups, ten in each according to irradiated time, they irradiated with the diode laser $810 \mathrm{~nm}$, at same power of $200 \mathrm{~mW}$, different irradiation time (2 and 10) minutes for the first and second group respectively.

- Twenty specimens of dental ceramic divided into two groups, ten in each according to irradiated power, they irradiated with diode laser810 nm, at same duration of one minute, different power of (30 and 500) mW for first group and the second one respectively.

- After the irradiation of the all specimens, the hardness test was measured (post-test).

- The comparison between (pre-test) and (post-test) will be done.

\section{Results and Discussion}

The results of irradiation with diode laser $810 \mathrm{~nm}$, power $200 \mathrm{~mW}$, at two different duration time (2 and 10) minutes, were listed in Table 1 and Table 2 respectively .

The hardness for ten specimens measured before and after irradiation by the laser diode laser $810 \mathrm{~nm}$, power 200 $\mathrm{mW}$, at two different duration time (2 and 10) minutes, were plotted in Figure 4 and Figure 5 respectively.

The comparison of the hardness average change at irradiation time two and ten minutes, at constant irradiation power at $200 \mathrm{~mW}$, Figure 6, shows little increasing in hardness with increasing irradiation time from two to ten

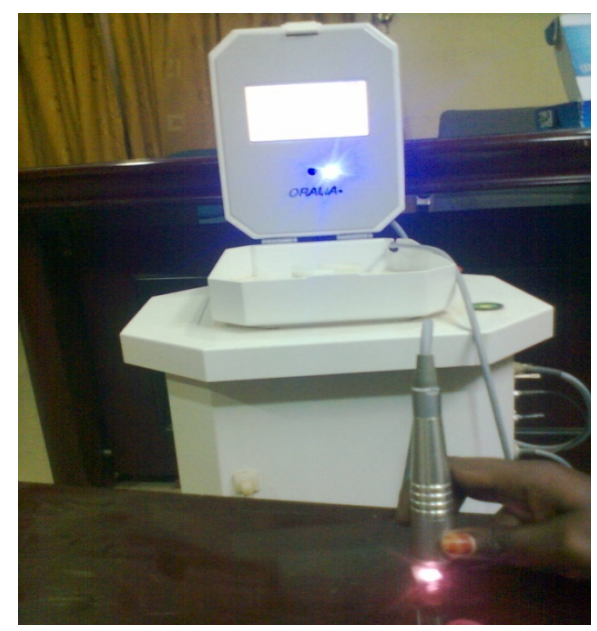

Figure 2. Irradiation of specimens by diode laser $(810 \mathrm{~nm})$.

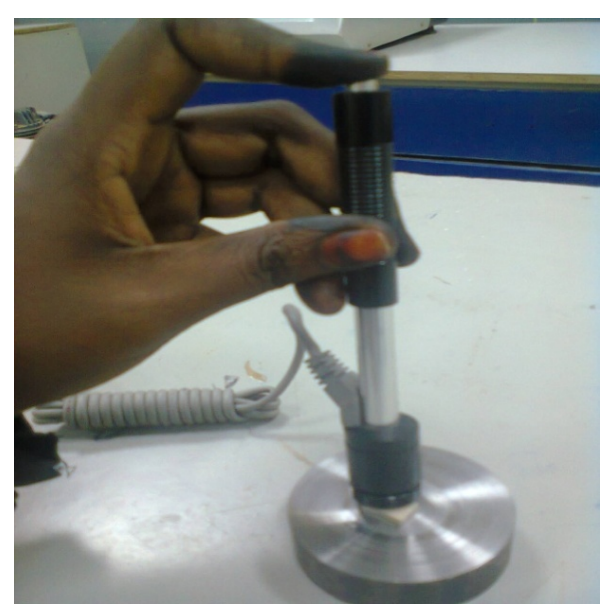

Figure 3. The method of hardness measured. 
Table 1. Measurement of hardness of dental ceramic specimens irradiated by diode laser $810 \mathrm{~nm}$, and power of $200 \mathrm{~mW}$ for two minutes.

\begin{tabular}{cccccccccccc}
\hline Specimen Number & 1 & 2 & 3 & 4 & 5 & 6 & 7 & 8 & 9 & 10 & Means \\
\hline (pre-test) (HB) & 64 & 53 & 38 & 58 & 55 & 51 & 55 & 46 & 56 & 56 & 51.1 \\
(post-test) (HB) & 87 & 57 & 54 & 56 & 65 & 57 & 67 & 51 & 47 & 65 & 60.6 \\
Hardness change (HB) & 23 & 4 & 16 & -2 & 10 & 6 & 12 & 5 & -12 & 9 & 9.5 \\
Change\% & 35.94 & 7.55 & 42.11 & -3.45 & 18.18 & 11.76 & 21.82 & 10.87 & -34.29 & 16.07 & 18.59 \\
\hline
\end{tabular}

Table 2. Measurement of hardness of dental ceramic specimens irradiated by diode laser $810 \mathrm{~nm}$, and power of $200 \mathrm{~mW}$ for ten minutes.

\begin{tabular}{ccccccccccccc}
\hline Specimen Number & 1 & 2 & 3 & 4 & 5 & 6 & 7 & 8 & 9 & 10 & Means \\
\hline (pre-test) (HB) & 39 & 37 & 37 & 56 & 45 & 31 & 53 & 33 & 34 & 39 & 40.4 \\
(post-test) (HB) & 50 & 53 & 49 & 77 & 56 & 36 & 51 & 41 & 45 & 43 & 50.1 \\
Hardness change (HB) & 11 & 16 & 12 & 21 & 11 & 5 & -2 & 8 & 11 & 4 & 9.7 \\
Change\% & 28.21 & 43.24 & 37.50 & 37.50 & 24.44 & 16.13 & -3.77 & 24.24 & 32.35 & 10.26 & 24.01 \\
\hline
\end{tabular}

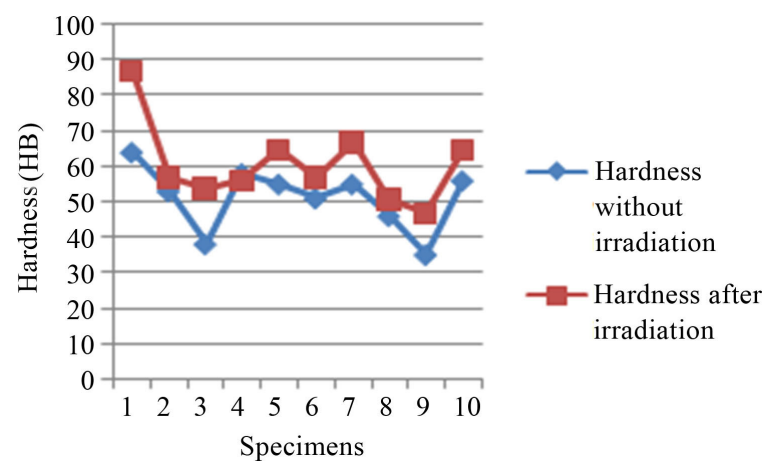

Figure 4. Measurement of hardness of dental ceramic specimens before and after irradiated by diode laser $810 \mathrm{~nm}$ and power $200 \mathrm{~mW}$ for two minutes.

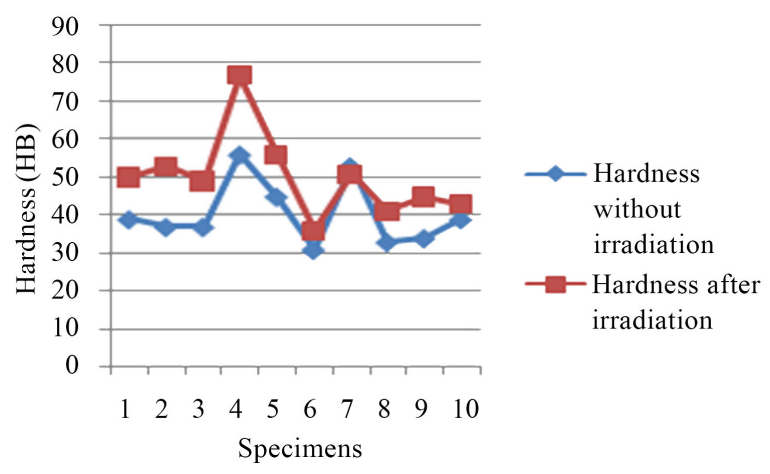

Figure 5. Measurement of hardness of dental ceramic specimens before and after irradiated by diode laser $810 \mathrm{~nm}$ and power $200 \mathrm{~mW}$ for ten minute.

minutes.

The hardness average change and the percentage of hardness increase with little ratio for irradiation time two to ten minutes, the different between the measurement as shown in Figure 7. 
Irradiation with (30 and 500) $\mathrm{mW}$ at duration one minute:

The results of irradiated with power $30 \mathrm{~mW}$ and $500 \mathrm{~mW}$ at duration one minute were listed in Table 3, and Table 4 respectively.

When we irradiate ten specimens of dental ceramic with diode laser $810 \mathrm{~nm}$ at power $30 \mathrm{~mW}$, the hardness for these specimens was changes. The hardness increases after irradiation time of one minute. The effective of irradiation specimens measured as hardness. Figure 8 shows the changeable of hardness for all ten specimens.

Figure 9 shows plot of increasing of hardness for ten specimens after irradiation with diode laser $810 \mathrm{~nm}$ at

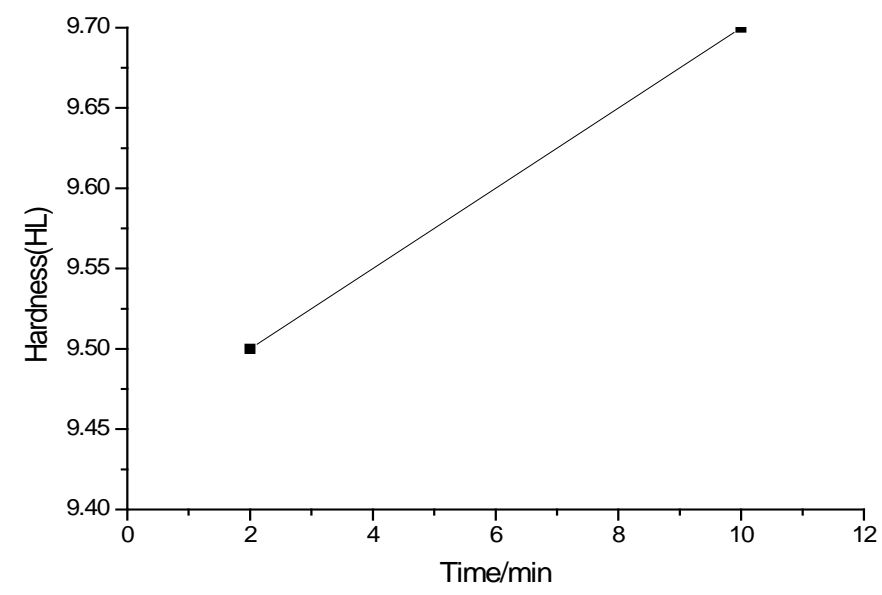

Figure 6. Comparison of hardness measurementfor irradiation time two and ten minute, and t power of $200 \mathrm{~mW}$.

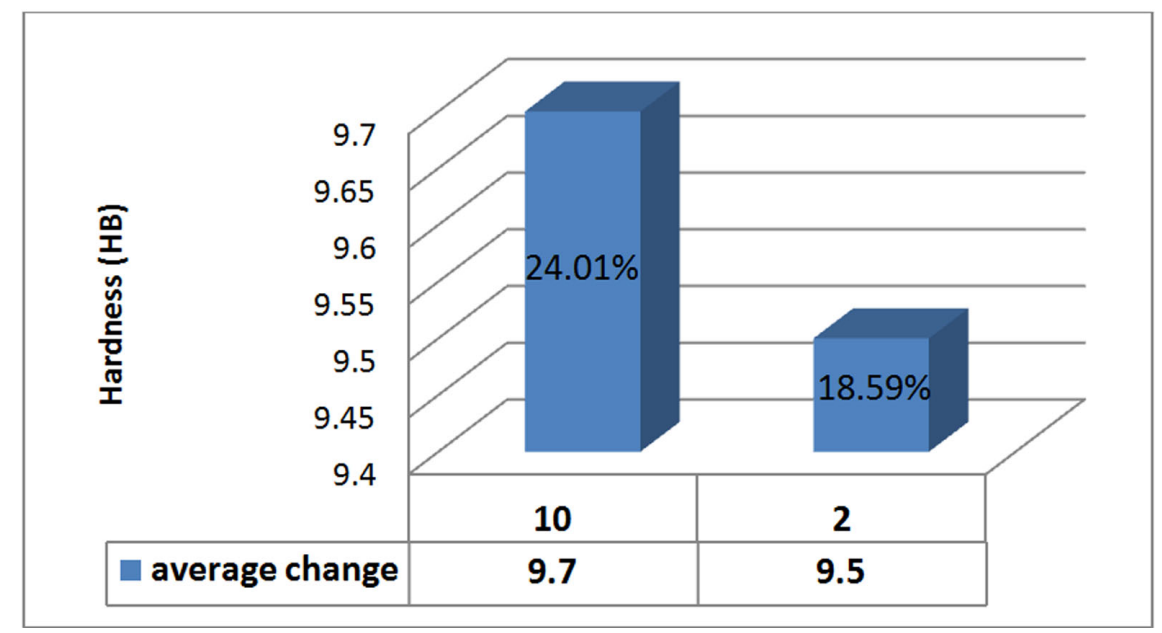

Figure 7. Measurement of hardness average change and the percentage of hardness for irradiation time two and ten minutes.

Table 3. The hardness measurement of dental ceramic irradiated with diode laser $810 \mathrm{~nm}$ and power of $30 \mathrm{~mW}$, for one minute.

\begin{tabular}{cccccccccccc}
\hline Specimen Number & 1 & 2 & 3 & 4 & 5 & 6 & 7 & 8 & 9 & 10 & Means \\
\hline (pre-test) (HB) & 38 & 32 & 41 & 39 & 35 & 37 & 37 & 35 & 38 & 40 & 37.2 \\
(post-test) (HB) & 40 & 36 & 47 & 47 & 42 & 45 & 47 & 36 & 48 & 52 & 44 \\
Hardness change (HB) & 2 & 4 & 6 & 8 & 7 & 8 & 10 & 1 & 10 & 12 & 6.8 \\
Change\% & 5.26 & 12.50 & 14.63 & 20.51 & 20 & 21.62 & 27.03 & 2.86 & 26.32 & 30 & 18.28 \\
\hline
\end{tabular}


Table 4. The hardness measurement of dental ceramic irradiated with diode laser $810 \mathrm{~nm}$ at power of $500 \mathrm{~mW}$, for one minute.

\begin{tabular}{cccccccccccc}
\hline Specimens Number & 1 & 2 & 3 & 4 & 5 & 6 & 7 & 8 & 9 & 10 & Means \\
\hline Hardness without irradiation (HB) & 32 & 35 & 38 & 39 & 32 & 35 & 37 & 35 & 32 & 35 & 35 \\
Hardness after irradiation (HB) & 35 & 38 & 42 & 48 & 28 & 39 & 41 & 37 & 33 & 35 & 37.6 \\
Hardness change (HB) & 3 & 3 & 4 & 9 & -4 & 4 & 4 & 2 & 1 & 0 & 2.6 \\
Change \% & 9.38 & 8.57 & 10.53 & 23.08 & -12.50 & 11.43 & 10.81 & 5.71 & 3.13 & 0 & 7.43 \\
\hline
\end{tabular}

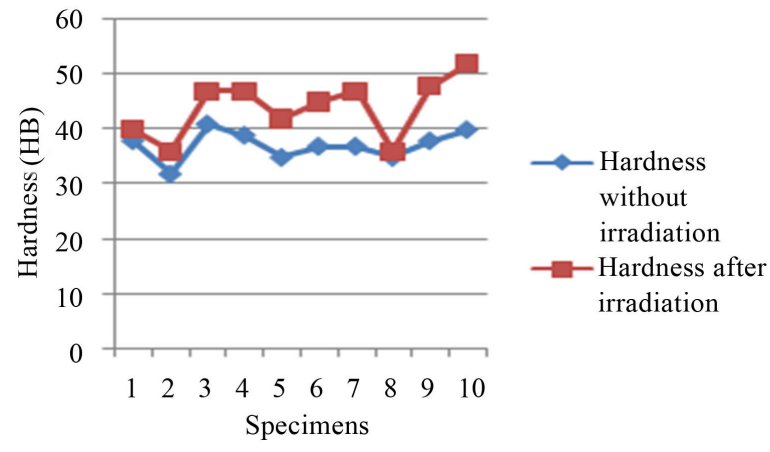

Figure 8. Measurement of hardness of dental ceramic specimens before and after irradiated by diode laser $810 \mathrm{~nm}$ and power $30 \mathrm{~mW}$ for one minute.

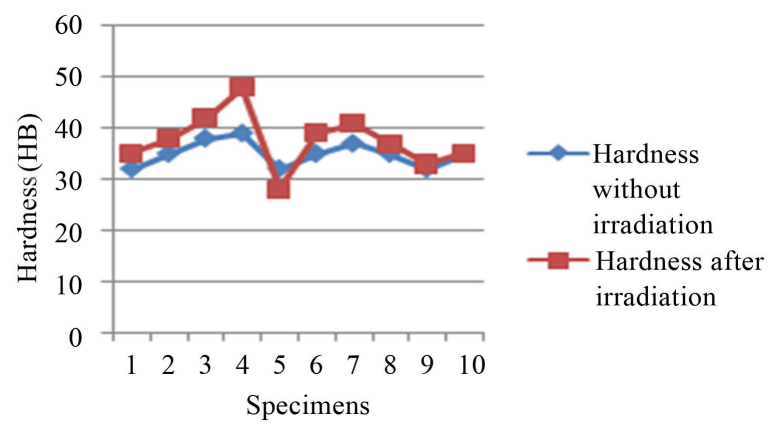

Figure 9. Shows plot of increasing of hardness for ten specimens after irradiation with diode laser $810 \mathrm{~nm}$ at power of $500 \mathrm{~mW}$, and irradiation time one minute.

power of $500 \mathrm{~mW}$, and irradiation time one minute.

The comparison of hardness average change at constant irradiation time at one minute, was shown on Figure $\mathbf{1 0 .}$

From Figure 10 one was investigatedthat the hardness of dental ceramic was decrease gradually with the irradiationincrease from (30 to 500) $\mathrm{mW}$.

The comparison of the hardness percentage of the sample with irradiated by $30 \mathrm{~mW}$ to $500 \mathrm{~mW}$ at one minute was plotted on Figure 11.

Figure 11 shows that the hardness average of the specimens changed, when the irradiated power was changed. The inverse relation was obtainedbetween the percentage of hardness and irradiated power of diode laser, (810 nm) and duration time (1 minute).

Discussion of Results of Irradiation with 810nm and Power 30, 200, $500 \mathrm{~mW}$ :

Based on obtained results, it was noted that an irradiation of specimens with diode laser 810 nm, had increase in hardness of dental ceramic.

In irradiation with power $200 \mathrm{~mW}$, achieved that at duration two minutes the hardness (18.59\%) increased but not large compared with $(24.01 \%)$ at irradiation time ten minutes, here we concluded that the increase in dura- 


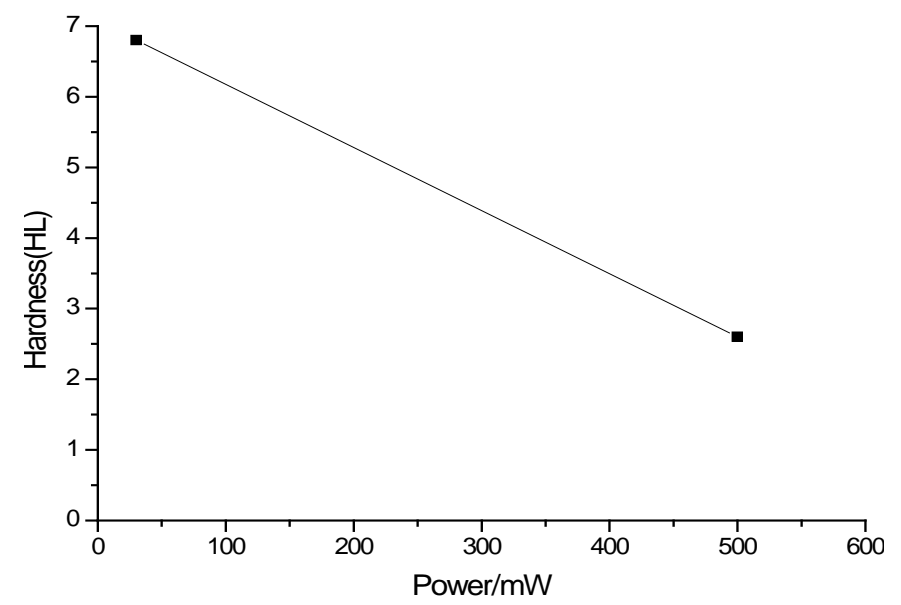

Figure 10. Comparison of the hardness measurement for irradiation time one minute and power of $30 \mathrm{~mW}$ and $500 \mathrm{~mW}$.

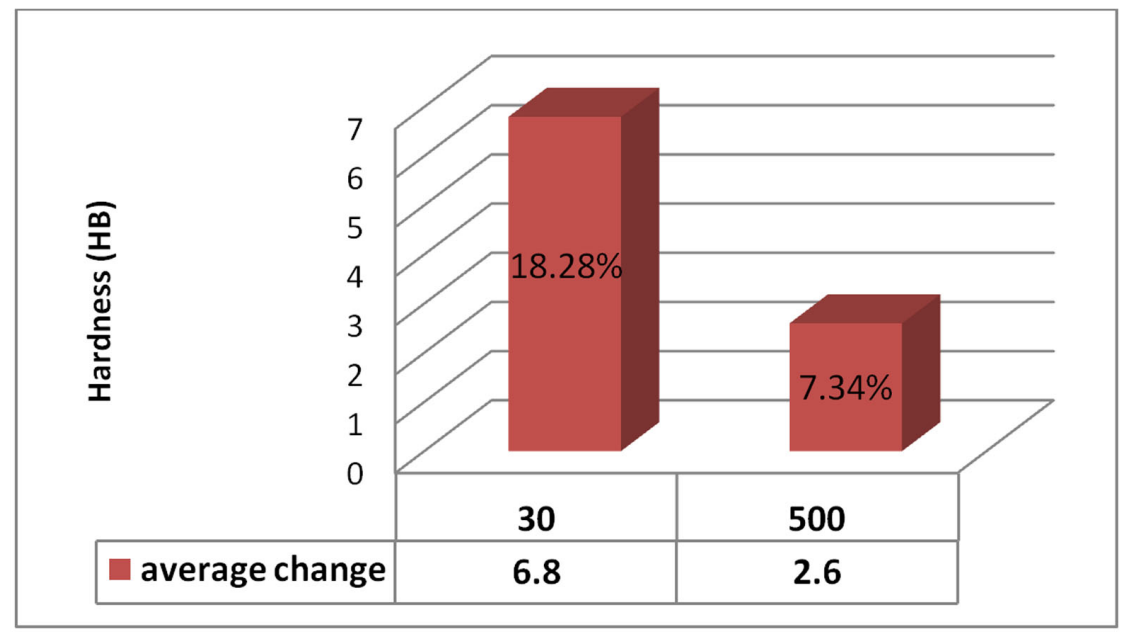

Figure 11. Measurement of hardness average change and the percentage of hardness for irradiation time one minute, at power of $30 \mathrm{~mW}$ and $500 \mathrm{~mW}$.

tion to longest time intervals has no influence in the hardness at irradiation with diode laser $810 \mathrm{~nm}$.

In irradiation with low power $(30 \mathrm{~mW})$ the hardness percentage was $(18.28 \%)$ compared to high power (500 $\mathrm{mW}$ ) it decrease to (7.34\%).

\section{Conclusion}

From the obtained results it can be concluded that, the highest ratio of the hardness is achieved at low power laser irradiation (30 mW). While low ratio of hardness obtained at high power irradiation (500 mW), also at irradiation with diode laser $(500 \mathrm{~mW})$, the dental ceramic with white color becomes very white. The high power caused heat in the dental ceramic material which in turn change the properties of the material, but hardness dose not increase by the large ratio.

\section{References}

[1] Ahluwalia, G.S. (2009) Cosmetic Application of Laser and Light-Based System, William Andrew, 101 (Inc USA).

[2] Gary, N. and Gary, A. (1983) Dye Stability under Excaimer Laser Pumping. Applied Physics B, 30, 109-166.

[3] Brackmann, U. (1986) Lambdachrome Laser Dyes. First Edition.

[4] Gary, N. and Gary, A. (2010) Text Book of Operative Dentistry. Jaypee Brothers, Medical Publishers. 
[5] Lakshmanan, A. (2012) Sintering of Ceramics_ New Emerging Techniques. InTech, JanezaTrdine 9, 51000 Rijeka, Croatia.

[6] Touati, P. and Nathanson, D. (1999) Esthetic Dentistry and Ceramic Resoration. New York, NY, USA.

[7] Ora-laser jet, Oralia Medical Gmbh, Instruction Manual Oralia Company-Germany.

[8] Czichos, H., Saiato, T., Leslie, L. and Smith, R. (2006) Hand Book of Material Measurement Method. Springer Science+Business Media, Inc.

[9] Information Provided by Shimadzu, Scientific Instrument.htm. 